


\title{
A INTEGRAÇÃO ENERGÉTICA NO MERCOSUL COM BASE NO DESENVOLVIMENTO E NA SUSTENTABILIDADE
}

\author{
Luiz Alberto Blanchet* \\ Arlei Costa Junior ** \\ Pontifícia Universidade Católica do Paraná
}

\begin{abstract}
Resumo
O presente trabalho se propõe a fazer uma análise do que é uma integração energética no Mercosul que atenda aos conceitos de desenvolvimento e sustentabilidade. Para isso, busca um olhar mais profundo no conceito de energia e em suas diversas formas de manifestação, com vistas a um entendimento do que é desenvolvimento e se ele seria sempre incremental, para então explorar o conceito de sustentabilidade, de forma a chegar à compreensão do desenvolvimento sustentável dentro da ótica antropocêntrica e ecocêntrica. Na sequência, apresentam-se o histórico e o fundamento jurídico do Mercosul e de seus órgãos, para, em seguida, analisar como tem se dado a integração energética entre seus membros e vizinhos geográficos, em especial quanto ao gás natural e à energia elétrica. Conclui-se tecendo considerações com base nos conceitos apresentados, sobre a relevância da integração e interligação energéticas entre os países-membros, e como isso contribui para o desenvolvimento sustentável. A metodologia utilizada foi a dedutiva, mediante uma pesquisa qualitativa e exploratória, bem como uma análise de obras relevantes sobre o tema.
\end{abstract}

Palavras-chave: energia, desenvolvimento sustentável, Mercosul, integração energética, interligação elétrica.

Recepção: 4 Abril 2018; Evaluação: 11 Outubro 2018; Aprovação: 16 Outubro 2018

Pontifícia Universidade Católica do Paraná (PUC-PR), Curitiba, Paraná, Brasil. E-mail: blanchet@blanchet. adv.br

** Pontifícia Universidade Católica do Paraná (PUC-PR), Curitiba, Paraná, Brasil. E-mail: arleijunior@gmail. com 


\title{
ENERGY INTEGRATION IN MERCOSUR BASED ON DEVELOPMENT AND SUSTAINABILITY
}

\author{
Luiz Alberto Blanchet \\ Arlei Costa Junior \\ Pontifícia Universidade Católica do Paraná
}

\begin{abstract}
The present work intends to make an analysis of what is an energy integration in Mercosur that meets the concepts of development and sustainability. For this, it seeks a deeper look at the concept of energy and its various forms of manifestation, aiming at an understanding of what development is and whether it would always be incremental, in order to explore the concept of sustainability in order to achieve an understanding of sustainable development within of the anthropocentric and ecocentric view. Following is the history and legal basis of Mercosur and its organs, and then analyze how has been given the energy integration between its members and geographic neighbors, especially regarding natural gas and electric energy. It concludes by elaborating considerations based on the concepts presented, on the relevance of energy integration and interconnection between member countries, and how this contributes to sustainable development. The methodology used was deductive, through a qualitative and exploratory research, as well as an analysis of relevant works on the theme.
\end{abstract}

Keywords: energy, sustainable development, Mercosur, energy integration, electrical interconnection.

Received: April 4, 2018; reviewed: October 11, 2018; accepted: October 16, 2018. 


\section{Introdução}

O presente trabalho pretende analisar se a integração energética no Mercado Comum do Sul (Mercosul) vem a atender aos conceitos de desenvolvimento e sustentabilidade. Para alcançar esse objetivo, considera-se necessário um entendimento mais intrínseco do que é energia e suas diversas formas de manifestação, e da evolução histórica das formas de energia que a humanidade tem conseguido manipular para transformá-la em atividades úteis aos seres humanos.

Na sequência, buscou-se um entendimento do que é desenvolvimento e se ele evolui positivamente no tempo, para então explorar o conceito de sustentabilidade, de forma a alcançar a compreensão do desenvolvimento sustentável. Existe uma avaliação subjetiva se o desenvolvimento foi positivo ou negativo, conforme a ótica realizada para essa análise, e as principais correntes são a antropocêntrica e a ecocêntrica, cujos conceitos básicos serão tratados neste trabalho.

Em seguida, apresentam-se as origens e a evolução histórica e jurídica do Mercosul e de seus órgãos, para, na sequência, analisar como tem se dado a integração energética entre seus membros e países vizinhos, no que se refere ao gás natural e à energia elétrica. Apresentam-se uma evolução histórica das centrais binacionais e das interligações elétricas existentes, bem como algumas estatísticas de consumo interno e exportação de energia.

O artigo busca conclusões valendo-se das premissas apresentadas, para deduzir sobre a relevância da integração e interligação energética entre os países-membros do Mercosul, e se isso tem contribuído para o desenvolvimento sustentável. Para isso, utilizará a metodologia dedutiva, com a realização de uma pesquisa qualitativa e exploratória.

\section{A energia elétrica}

Até hoje, não se tem um perfeito entendimento do que é energia, embora nossas principais teorias científicas sustentem que a energia do universo é uma quantidade finita e imutável, não podendo ser gerada ou destruída, mas apenas modificada 
em sua forma aparente. Nesse sentido, vem o conceito de energia relacionado à capacidade de realização de trabalho. ${ }^{1}$

Halliday ${ }^{2}$ coloca que ainda não foi encontrada uma exceção ao princípio da conservação da energia, sendo este um dos princípios basilares de todo o conhecimento científico e que possibilita desenvolver equações com a premissa de que a quantidade total de energia de um sistema fechado não se modifica. Ou seja, numa equação, os dois termos dessa igualdade significam que a energia se transforma de um tipo em outro, mas ela se conserva.

Entende-se, no senso comum, a energia como a capacidade de produzir um trabalho ou realizar uma ação. Notoriamente relevante tanto na química quanto na biologia, e mesmo em economia e outras áreas de cunho social, a energia se destaca como ponto fundamental, uma vez que o seu comércio move anualmente quantidades enormes de dinheiro.

O conceito de energia permeia toda a atividade científica, e os modelamentos científicos levaram a simplificações aritméticas, que denominamos leis, que regem o comportamento da energia e sua capacidade de gerar trabalho.

Para mensurarmos uma quantidade de energia, utilizamos uma unidade de medida que denominamos joule, que, por sua vez, em sua análise dimensional, percebemos que é uma unidade derivada, que equivale a um quilograma metro quadrado por segundo quadrado. Essa unidade de energia pode ser convertida em outras unidades mais populares em alguns contextos específicos; assim, embora a unidade oficial seja o

1 "Quando se fala em energia devemos ter muita cautela, porque não se tem uma definição concisa sobre energia de um modo geral. O que devemos saber é que a existência da matéria depende diretamente da existência de energia. A palavra energia deriva do grego enérgeia, que significa 'força em ação'. Devemos lembrar aqui que a energia de todo o universo é constante, ou seja, nada se cria, nada se perde, tudo se transforma. Cientificamente, o conceito de energia está relacionado principalmente à realização de trabalho. Em princípio, podemos dizer que 'Energia é a grandeza que avalia a capacidade de um sistema realizar trabalho'. No SI [Sistema Internacional de Unidades] o trabalho realizado é expresso na mesma unidade que mede a energia: N.m ou kg.m²/s2, que equivale à unidade joule (lê-se: jaule)". Conceitos básicos. https:// pt.scribd.com/doc/50498774/Conceitos-Basicos, consultado em 23 dez. 2017.

2 "Tecnicamente, a energia é uma grandeza escalar associada ao estado de um ou mais objetos; entretanto, esta definição é excessivamente vaga para ser útil para quem está começando. [...] A energia pode ser transformada de uma forma para outra e transferida de um objeto para outro, mas a quantidade total é sempre a mesma (a energia é conservada). Até hoje, nunca foi encontrada uma exceção desta lei de conservação da energia". Halliday, David, Robert Resnick e Jearl Walker, Fundamentos de fisica, volume 1: mecânica. $8^{a}$ ed. (Rio de Janeiro: LTC, 2008), 153. 
joule, frequentemente se utiliza o (quilo)watt-hora ( $\mathrm{kWh}$ ) para medir o consumo de energia elétrica.

O watt-hora corresponde à energia transformada quando um dispositivo com potência de 1 watt opera durante um intervalo de tempo de 1 hora. Uma lâmpada cuja potência nominal é $60 \mathrm{~W}$, a cada 12 horas de funcionamento, transforma $720 \mathrm{Wh}$ $(0,72 \mathrm{kWh})$ de energia elétrica em outras formas de energia ( $720 \mathrm{Wh}=60 \mathrm{~W} \times 12 \mathrm{~h})$.

A energia normalmente torna-se útil quando é transformada de uma forma em outra, e essa transferência de energia denomina-se trabalho, sobre o qual Halliday ${ }^{3}$ faz a seguinte definição: "Nas transferências de energia através de uma força, dizemos que um trabalho W é realizado pela força sobre o objeto. [...] Trabalho, portanto, é a energia transferida; realizar trabalho é o ato de transferir energia. O trabalho tem a mesma unidade que a energia e é uma grandeza escalar".

As sociedades humanas dependem cada vez mais de um elevado consumo energético para sua subsistência. Para isso, foram sendo desenvolvidos ao longo da história diversos processos de transformação, transporte e armazenamento de energia. Conforme o disposto pela primeira lei da termodinâmica, só existem, além da energia pura radiante, duas formas de energia armazenadas em um sistema: a potencial e a cinética. No cotidiano, entretanto, elas acabam recebendo nomes específicos que geralmente fazem referência explícita à natureza do sistema envolvido no armazenamento ou às plantas industriais onde estas são levadas à transformação.

Assim, tem-se a energia hidráulica como sinônimo de energia potencial gravitacional ou mesmo cinética armazenada nas águas de uma represa hidroelétrica, que, conforme o nome diz, cuida da conversão de energia "hidráulica" em energia potencial elétrica; a energia nuclear para a energia potencial associada à interação nuclear forte, ou até mesmo, em senso comum, para a energia elétrica produzida em termoelétricas cujas fontes de energia térmica são reatores nucleares; a energia eólica associada à energia cinética de movimento das massas de ar (ventos); a energia solar associada à radiação eletromagnética com origem no Sol e a energia geotérmica associada à energia térmica do interior da terra. Dessa forma, chega-se aos tipos de energia que os seres humanos têm utilizado em sua evolução histórica, para garantir sua sobrevivência e melhorar sua condição de segurança, conforto e conhecimento.

3 Halliday, Resnick e Walker, Fundamentos de física, 154. 
A energia gerada pelo sol e irradiada pelo sistema solar, que foi e continua sendo absorvida pelo planeta nesses bilhões de anos desde sua formação, é a sua principal fonte de energia. A vida em nosso planeta iniciou de forma muito simples e evoluiu para a formação de vegetais. Estes, em algum momento, começaram a realizar a fotossíntese —reação que absorve luz solar e a armazena em uma ligação química一, que, além de servir para a alimentação dos próprios vegetais, propiciou a evolução dos demais seres vivos, que, em sua quase totalidade, estão adaptados a sobreviver alimentando-se de outros animais ou vegetais. Portanto, a cadeia alimentar dos seres vivos tem em sua base a energia armazenada pelos vegetais quando realizam a fotossíntese.

Os combustíveis fósseis são o resultado da decomposição de matéria orgânica de origem animal e vegetal submetida a determinadas condições de temperatura e pressão, cuja energia contida em suas ligações químicas é oriunda da fotossíntese, ou seja, em última análise, da energia solar que as plantas conseguiram armazenar via fotossíntese. Toda a energia solar acumulada nessas reações químicas nesses bilhões de anos, desde que surgiu a vida na Terra, está concentrada basicamente nos combustíveis fósseis, nos animais e nos vegetais vivos, bem como no solo na forma de matéria orgânica. Nesse sentido, Michio Kaku explica que toda a energia vem do Sol, mesmo o petróleo e o carvão, que são, em certo sentido, a luz solar concentrada, que incidiu sobre as plantas e os animais de milhões de anos atrás.

A enorme quantidade de energia solar armazenada quimicamente na matéria orgânica e principalmente nos combustíveis fósseis nesses bilhões de anos no planeta, e a forma relativamente barata de transformar essa energia via dispositivos que a geram calor e movimento, contribuiu para a quase completa dependência atual dos combustíveis fósseis, na forma de petróleo, gás natural e carvão, para o fornecimento de energia.

Os combustíveis fósseis são um tipo de energia que até se renova, pois os processos físico-químicos que os criaram continuam em ação, mas em uma taxa muito desproporcional à do seu consumo; assim, são considerados como energia não renovável.

\footnotetext{
4 "Em última análise, toda a energia vem do sol. Mesmo que o petróleo e o carvão sejam, em certo sentido, a luz solar concentrada, representando a energia que caiu sobre as plantas e animais de milhões de anos atrás. Como consequência, a quantidade de energia solar concentrada armazenada dentro de um galão de gasolina é muito maior do que a energia que se pode armazenar em uma bateria. Esse foi o problema fundamental de Edison, no século passado, e é o mesmo problema hoje". Kaku, Michio, A Física do Futuro (Lisboa: Bizâncio, 2011), 209.
} 
A evolução do conhecimento científico no último século, notadamente no campo da física quântica e de partículas, levou a grandes avanços na compreensão e desenvolvimento de dispositivos de geração e armazenamento de energia; no entanto tudo indica que, no curto prazo, não há uma solução tecnológica econômica o suficiente para a rápida substituição do uso dos combustíveis fósseis. Nesse sentido, Michio Kaku analisa que o mais provável será uma mistura de formas de geração de energia, como eólica, solar, hidrelétrica, sem nenhuma predominante, e que a contínua queda dos preços dos painéis solares, combinada com a ascensão dos preços dos combustíveis fósseis, trará a viabilidade econômica da tecnologia de geração por painéis solares.

Há um rol de tecnologias conhecidas para a geração de energia, que já estão substituindo ou devem ir substituindo gradualmente o uso de combustíveis fósseis, dentre as quais se destacam a energia hidrelétrica, biomassa, energia eólica, a energia solar (células solares), a energia oceânica e a energia nuclear por cisão; e outras que estão em desenvolvimento e devem, no futuro, se tornar viáveis técnica e economicamente, tal como a energia por fusão nuclear.

\section{Desenvolvimento e sustentabilidade}

O termo "desenvolvimento" leva ao entendimento de algo que evolui no tempo de um estado mais primitivo para um estado mais avançado, e assim pode ser compreendido dentro de uma ampla gama de concepções, conforme a ótica do observador. Uma das questões que já surgem inicialmente é se o desenvolvimento ou a evolução é sempre positivo, ou seja, se, com a passagem do tempo, o objeto observado sempre vai de um estado mais primitivo para um estado mais avançado.

O próprio conhecimento científico tem se desenvolvido rapidamente, e os modelamentos teóricos atuais podem e tendem a ser ampliados ou substituídos por outros que expliquem os fatos com mais precisão. A observação e a experimentação com frequência demonstram que os modelos existentes são incompletos ou conflitantes com a realidade, o que leva à constatação da necessidade de aprimorar o conhecimento científico e ao consequente aumento da capacidade de previsão dos eventos futuros.

Kaku, A Física do Futuro, 208. 
Sob uma ótica antropocêntrica, pode-se entender que houve um grande desenvolvimento na evolução da vida terrestre, até alcançar a vida inteligente e autoconsciente, isto é, o ser humano. Estendendo essa visão antropocêntrica, o ambiente ideal seria aquele adequado à preservação da espécie humana e do seu habitat natural, incluindo tudo que é necessário à preservação da vida humana no transcurso do tempo, do que se obtém a noção de sustentabilidade.

A sustentabilidade implica a manutenção das condições necessárias para sustentar um processo ou sistema por um determinado tempo. Então, nessa visão antropocêntrica, para que a vida humana seja possível, há a necessidade de várias condições, e a manutenção dessas condições ideais ao longo do tempo é o que se entende por sustentabilidade da vida humana.

A Comissão Mundial sobre o Meio Ambiente apresentou, em 1987, o Relatório Brundtland, ${ }^{6}$ que é considerado o primeiro documento que utilizou a expressão "desenvolvimento sustentável", definindo-a como: "o desenvolvimento que atende às necessidades do presente sem comprometer a possibilidade de as gerações futuras atenderem às suas próprias necessidades", e relacionou os conceitos de desenvolvimento e sustentabilidade.

De uma forma mais ampla, o "desenvolvimento sustentável" poderia ser entendido como "as condições necessárias para sustentar um processo ou sistema que esteja em desenvolvimento ao longo do transcurso do tempo". ${ }^{7} \mathrm{Na}$ ótica antropocêntrica, temos a vida humana como o sistema a ser sustentado.

Estima-se que a vida tenha surgido na Terra há pouco mais de 3,5 bilhões de anos. ${ }^{8}$ Ao considerar que a idade do planeta é calculada em 4,5 bilhões de anos, a vida surgiu de forma relativamente rápida e veio evoluindo em meio a eventos cataclísmicos que, por várias vezes, quase a extinguiram. Se o tempo de surgimento do planeta Terra até os dias atuais estivesse numa escala equivalente à duração de um

6 Ipiranga, Ana Silva Rocha, Godoy, Arilda Schmidt e Brunstein, Janette, "RAM. Revista de Administração Mackenzie", RAM, Rev. Adm. Mackenzie (On-line) 12, n. 3 (junho 2011), consultado em 22 dez. 2017: 1. http://www.scielo.br/scielo.php? script=sci_arttext\&pid=S1678-69712011000300002.

7 Blanchet, Luiz Alberto e Costa Junior, Arlei, "Desenvolvimento e Sustentabilidade na Geração de Energia Elétrica", Direito, sociedade e desenvolvimento. Revista Jurídica Eletrônica 9, vol. 5 (2017), consultado em 13 out. 2018. http://www.artedigital.ufrrj.br/SEER/index. php?journal=RJEDSD\&page=article\&op=download\&path\%5B\%5D=3907\&path\%5B\%5D=2510.

8 Branco, Pércio de Moraes, "Breve História da Terra", consultado em 23 dez. 2017. http://www.cprm.gov. br/publique/Redes-Institucionais/Rede-de-Bibliotecas---Rede-Ametista/Canal-Escola/Breve-Historia-da-Terra-1094.html. 
ano terrestre, na data equivalente a 28 de março já existiriam as primeiras bactérias no planeta, e o Homo Sapiens surgiria no dia 31 de dezembro, às 23h36min5ls.

Nessa escala temporal, a ótica antropocêntrica do desenvolvimento sustentável parece pretenciosa, mas a espécie humana, nessa fração mínima de tempo, atingiu uma superioridade intelectual tão significativa com relação às demais espécies que dominou todos os continentes com o aumento expressivo de sua população e vem modificando de tal forma o planeta que já se deu conta que precisa adequar o uso dos recursos naturais aa níveis sustentáveis de crescimento.

Talvez a grande conquista do ser humano tenha sido desenvolver o conhecimento científico a ponto de compreender, ainda que atualmente de forma bastante incompleta, o funcionamento de todo o universo. Esse conhecimento científico, incremental e contínuo, iniciado com a comunicação oral e, logo, coma escrita —a qual possibilitou que as gerações futuras aprendessem com os escritos das gerações anteriores e pudessem acrescentar conhecimento documentado, que culminou no princípio científico—, trouxe razoabilidade e previsibilidade ao conhecimento.

O último século da existência humana marcou um período muito bem-sucedido para o crescimento populacional e econômico, do que ninguém parece duvidar da capacidade humana para enfrentar os desafios do crescimento; contudo, numa perspectiva dos sistemas do planeta Terra, a história de sucesso humano não parece tão positiva. ${ }^{9}$

O antropocentrismo tem seu contraponto no ecocentrismo, cuja ética tende a se basear em reivindicações de valor intrínseco não antropocêntrico (biocêntrico, ecocêntrico), e sua concepção de justiça se estende a outras espécies, a lugares específicos e a sistemas naturais interativos, como comunidades bióticas. Essa é a base ética do ambientalismo ecológico, que se preocupa com a preservação da natureza, de sistemas naturais e de lugares e espécies específicos. O ambientalismo econômico tem o foco nas preocupações com o desperdício, com a ineficiência e com o uso imprudente da natureza e dos recursos naturais, bem como com o controle político

9 Tradução livre do autor. "The last century of human existence has marked a very successful period for population and economic growth. [...] Based on the human experience to date, no one seems to seriously doubt the ingenuity of humans to meet the growth challenges. [...] Yet, from an Earth systems perspective, the human success story is not so positive." World Economic Forum, "Harnessing the Fourth Industrial Revolution for the Earth", Fourth Industrial Revolution for the Earth Series (2017), consultado em 29 dez. 2017. http://www3.weforum.org/ docs/WEF_Harnessing_the_4IR_for_the_Earth.pdf 
da elite sobre esses recursos. Sua ética é contingente e utilitária, e sua concepção de justiça é materialista.

A busca da proteção ao meio ambiente leva a processos mais dispendiosos à atividade econômica, e várias soluções econômicas e jurídicas foram propostas, tais como taxas a serem pagas como uma espécie de indenização proporcional à poluição gerada. Nesse sentido, Ronald Coase, ${ }^{10}$ que tem uma visão utilitarista, argumenta que, independentemente de quem tem a responsabilidade de indenizar, existe uma solução ótima (ideal) para o caso concreto que será sempre a mesma e se fundamenta em valores de eficiência econômica para tanto. Assim, para ele, a solução ótima seria aquela menos custosa e que maximiza o ganho entre as partes em conflito indenizatório, e, nesse sentido, as leis e o direito apenas definiriam quem deveria pagar os custos, mas não poderiam modificar a solução ideal.

Douglass North ${ }^{11}$ acrescenta que o desempenho econômico também depende da redução dos custos de transação, e que as modificações nas instituições, quando conseguem alcançar modelos realísticos, promove uma melhora incremental na economia, que, ao longo do tempo, leva esse processo à eficiência econômica.

Amartya Sen adota um posicionamento diferente dos expostos, pois, embora seja antropocêntrico, não é utilitarista. Ele argumenta por uma nova racionalidade do desenvolvimento, voltada ao atendimento das necessidades humanas, focada na oferta de oportunidades e na qualidade de vida das pessoas e não apenas com vistas ao aumento da renda.

A análise do desenvolvimento apresentada neste livro trata as liberdades dos indivíduos como os blocos de construção básicos. A atenção é, portanto, especialmente dada à expansão das "capacidades" das pessoas para poderem levar o tipo de vida que valorizam e tem motivos para valorar. Essas capacidades podem ser reforçadas por políticas públicas, mas também, por outro lado, a direção da política pública pode ser influenciada pelo uso efetivo das capacidades participativas das pessoas. O relacionamento bidirecional é fundamental para a análise apresentada aqui. [...] O sucesso de uma sociedade deve ser avaliado, nesta visão, principalmente pelas liberdades substanciais que os membros dessa sociedade desfrutam. [...] Ter maior liberdade para fazer as coisas que

Coase, Ronald H., "The Problem of Social Cost", Journal of Law and Economics 3 (outubro 1960): 1-44.

11 North, Douglass Cecil, Institutions, institutional change and economic performance (Cambridge: University Press, 1990). 
tem razões para valorar é (1) significativo em si mesmo para a liberdade geral da pessoa, e (2) importante para promover a oportunidade da pessoa obter resultados valiosos. ${ }^{12}$

André Folloni argumenta que a Constituição brasileira, em conjunto com os tratados internacionais, prescreve rigorosas metas para o desenvolvimento sustentável, contudo esse é um conceito complexo que não pode ser bem compreendido pelo isolamento disciplinar do conhecimento. "Nesse sentido, explica que a teoria da complexidade pode oferecer aos cientistas jurídicos uma base segura sobre a qual teorias jurídicas podem ser construídas, valorizando e incluindo outras áreas da ciência que sejam necessárias para o conhecimento do objeto de estudo, permitindo um conhecimento multidisciplinar da lei e da realidade". ${ }^{13}$

Édis Milaré explica que a maior parte dos problemas que cercam o meio ambiente na atualidade gira em torno da questão do desenvolvimento sustentável. ${ }^{14}$ Vladimir Passos de Freitas ressalta que a questão ambiental constitui uma preocupação mundial que transcende fronteiras, tipo de economia, origem étnica e religiosa dos países. ${ }^{15}$

A Constituição brasileira adota a perspectiva antropocêntrica, quando trata da ordem econômica e financeira, em seu artigo 170, inciso VI, em que determina que deve ser observada a defesa do meio ambiente, buscando uma coexistência harmônica entre economia e meio ambiente. Scherwitz argumenta que, nessa "visão antropocêntrica, a pessoa humana é o destinatário da norma constitucional, e o homem é o único capaz de proteger e preservar o meio ambiente. De acordo

12 Tradução livre do autor. "The analysis of development presented in this book treats the freedoms of individuals as the basic building blocks. Attention is thus paid particularly to the expansion of the 'capabilities' of persons to lead the kind of lives they value-and have reason to value. These capabilities can be enhanced by public policy, but also, on the other side, the direction of public policy can be influenced by the effective use of participatory capabilities by the public. The two-way relationship is central to the analysis presented here. [...] The success of a society is to be evaluated, in this view, primarily by the substantive freedoms that the members of that society enjoy. [...] Having greater freedom to do the things one has reason to value is (1) significant in itself for the person's overall freedom, and (2) important in fostering the person's opportunity to have valuable outcomes". Sen, Amartya, Development as freedom (Nova York: Knoph, 2000), 18.

13 Folloni, André, "A complexidade ideológica, jurídica e política do desenvolvimento sustentável e a necessidade de compreensão interdisciplinar do problema", Revista Direitos Humanos Fundamentais 14, 1 (jan.-jun. 2014): 63-91.

14 Milaré, Edis, Direito do Ambiente (São Paulo: RT. ed. 8. rev. atual. e ampl., 2013), 45.

15 Freitas, Vladimir Passos de. "A desejada e complexa conciliação entre desenvolvimento econômico e proteção do meio ambiente no Brasil", Revista Direito Ambiental e Sociedade 4, 1 (semestral, 2014), consultado em 22 dez. 2017: 235-263. http://www.ucs.br/etc/revistas/index.php/direitoambiental/article/view/3692/2115. 
com essa visão, o bem ambiental está voltado para a satisfação das necessidades humanas, protegendo 'indiretamente' outras formas de vida". ${ }^{16}$

Isso parece decorrer do fato de atualmente a espécie humana ser a única reconhecidamente capaz de compreender e desenvolver o conhecimento científico, de forma a evitar que o sucesso de sua evolução venha a inviabilizar o seu próprio futuro. Nesse sentido, as ciências sociais, inclusive as ciências jurídicas, podem ajudar a compreender as restrições de condutas necessárias e a criação de uma convergência nas ações humanas direcionadas para alcançar a sustentabilidade com desenvolvimento.

\section{Mercosul}

O Mercosul surgiu pelo Tratado de Assunção, em 26 de março de 1991, tendo como signatários Argentina, Brasil, Paraguai e Uruguai, com o objetivo de formar um mercado comum, que viabilizaria a livre circulação de bens, serviços e capitais através da coordenação econômica e harmonização política e normativa.

O Tratado de Assunção, ${ }_{17}^{17}$ em seu artigo $9^{\circ}$, dispôs que a administração e execução do tratado e dos acordos específicos, bem como das decisões que se adotem em seu quadro jurídico durante o período de transição, estarão a cargo do Conselho do Mercado Comum e do Grupo do Mercado Comum. Esses órgãos estão compostos por representantes dos Ministérios de Relações Exteriores, da Economia e dos Bancos Centrais dos países participantes.

No Protocolo de Ouro Preto, ${ }^{18} \mathrm{em}$ 1994, foi deliberado sobre a estrutura institucional do Mercosul, que ficou constituído com seguintes órgãos: Conselho do Mercado comum (CMC); Grupo Mercado Comum (GMC); Comissão de Comércio do Mercosul (CCM); Comissão Parlamentar Conjunta (CPC); Foro Consultivo Econômico-Social (FCES) e Secretaria Administrativa do Mercosul (SAM). E, ainda, seu parágrafo único

16 Scherwitz, Débora Perilo, "As visões antropocêntrica, biocêntrica e ecocêntrica do direito dos animais no Direito Ambiental", Revista Direito e Sociedade 3, n. 1 (2015), consultado em 29 dez. 2017: 12. http://revista. zumbidospalmares.edu.br/images/stories/pdf/edicao-3/visoes-biocentrica-ecocentrica.pdf.

17 Decreto 350, de 21 de novembro de 1991. Brasil. Decreto n. 350, de 21 de nov. de 1991. Promulga o Tratado para a Constituição de um Mercado Comum entre a República Argentina, a República Federativa do Brasil, a República do Paraguai e a República Oriental do Uruguai (Tratado Mercosul), Brasília, DF, nov. 1991.

18 Protocolo de Ouro Preto. Brasil. Decreto 1.901, de 99 de maio de 1996. Artigos 28 e 29. Promulga o Protocolo Adicional ao Tratado de Assunção sobre a Estrutura Institucional do Mercosul (Protocolo de Ouro Preto), Brasília, DF, maio 1996. 
menciona que poderiam ser criados os órgãos auxiliares que se fizessem necessários à consecução dos objetivos do processo de integração. ${ }^{19}$ A seguir, relacionam-se os órgãos e suas atribuições.

I. CMC: órgão supremo do Mercosul, cuja função é conduzir politicamente o processo de integração. O CMC é formado pelos ministros de relações exteriores e de economia dos estados-partes, que se pronunciam através de decisões.

II. GMC: órgão decisório executivo do Mercosul, responsável de fixar os programas de trabalho e de negociar acordos com terceiros em nome do Mercosul, por delegação expressa do CMC. O GMC se pronuncia por resoluções e está integrado por quatro membros titulares e quatro membros alternos por país, dentre os quais constam necessariamente representantes dos ministérios das relações exteriores, dos ministérios da economia (ou equivalentes) e dos bancos centrais. O GMC será coordenado pelos ministérios das relações exteriores.

III. CCM: órgão encarregado de assistir o Grupo Mercado Comum; compete velar pela aplicação dos instrumentos de política comercial comum acordados pelos estados-partes para o funcionamento da união aduaneira, bem como acompanhar e revisar os temas e matérias relacionados com as políticas comerciais comuns, com o comércio infraMercosul e com terceiros países. A CCM será integrada por quatro membros titulares e quatro membros alternos por estado-parte e será coordenada pelos ministérios das relações exteriores.

IV. CPC: órgão representativo dos parlamentos dos estados-partes no âmbito do Mercosul. A CPC será integrada por igual número de parlamentares representantes dos estados-partes. Os integrantes da CPC serão designados pelos respectivos parlamentares nacionais, de acordo com seus procedimentos internos. A CPC procurará acelerar os procedimentos internos correspondentes nos estados-artes para a pronta entrada em vigor das normas emanadas dos órgãos do Mercosul e coadjuvará na harmonização de legislações e no avanço do processo de integração.

V. FCES: órgão de representação dos setores econômicos e sociais, com função consultiva, o qual se manifesta mediante recomendações no GMC.

19 Brasil. Protocolo de Ouro Preto, Artigos 28 e 29. 
VI. SAM: órgão de apoio operacional. A SAM será responsável pela prestação de serviços aos demais órgãos do Mercosul e terá sede permanente na cidade de Montevidéu.

O FCES teve seu regimento interno aprovado pelo GMC, em junho de 1996, contando com nove representantes de entidades empresariais, de trabalhadores e consumidores de cada estado-parte, e seu plenário; o maior e principal órgão de decisão está integrado por 36 delegados dos quatro países, devendo-se ressaltar que, além das recomendações previstas no Protocolo de Ouro Preto, seu regimento interno prevê também manifestação ao GMC por iniciativa própria.

Posteriormente, realizou-se o Consenso de Buenos Aires, em 2003, que, num momento político favorável, expandiu os horizontes do Mercosul no intuito de uma maior integração regional para competir no mercado globalizado; nesse sentido, Ferreira e Ribeiro ${ }^{20}$ colocam que "o bloco, antes limitado à promoção do comércio, assumiu o objetivo de promover o desenvolvimento com crescimento econômico e justiça social, baseado em valores comuns como a erradicação da pobreza e a promoção da democracia".

Nessa perspectiva, também se buscou uma aproximação do Mercosul das demandas dos cidadãos. A implementação do FCES, previsto no Protocolo de Ouro Preto, ${ }^{21}$ trouxe ares de participação popular no Mercosul.

Ferreira e Ribeiro ${ }^{21}$, no escopo da evolução histórica do Mercosul, argumentam que "o Mercosul passou por momentos de ampliação institucional em sua trajetória que buscaram responder às necessidades apresentadas para operacionalizar a busca pelo desenvolvimento, nas diferentes formas em que o mesmo foi compreendido: inicialmente na forma econômico-comercial e, posteriormente, incluindo temas sociais e políticos".

Para reduzir as assimetrias econômicas e possibilitar projetos de convergência estrutural, entre outros, foi criado o Fundo para a Convergência Estrutural do

20 Ferreira, Guilherme Augusto Guimarães e Clarissa Correa Neto Ribeiro, "A estrutura institucional do Mercosul: análise da evolução dos espaços de participação social", em Anais do II Simpósio Internacional Pensar e Repensar a América Latina, São Paulo, 2016, consultado em 12 fev. 2018. https://sites.usp.br/prolam/ wp-content/uploads/sites/35/2016/12/ Ferreira_ Ribeiro_II-Simposio-Internacional-Pensar-e-Repensar-a-America-Latina.pdf.

21 Protocolo de Ouro Preto. Decreto 1.901, de 9 de maio de 1996. Artigos 28 e 29. 
Mercosul (Focem). ${ }^{22}$ O Focem é um fundo destinado a financiar programas para promover a convergência estrutural; desenvolver a competitividade; promover a coesão social, em particular das economias menores e de regiões menos desenvolvidas, e apoiar o funcionamento da estrutura institucional e o fortalecimento do processo de integração. Os fundos são destinados aos países e entregues em caráter de doação não reembolsável para financiar até os $85 \%$ do valor elegível por eles apresentados. ${ }^{23}$

O aspecto ambiental não foi esquecido no Mercosul, e, em 22 de junho de 2001, foi assinada, em Assunção, no Paraguai, a ratificação do Acordo-Quadro sobre Meio Ambiente. ${ }^{24}$ Nesse documento, foi reiterado o compromisso com os princípios enunciados na Declaração do Rio de Janeiro sobre Meio Ambiente e Desenvolvimento, de 1992, com vistas a promover a proteção do meio ambiente e o aproveitamento mais eficaz dos recursos disponíveis mediante a coordenação de políticas setoriais, com base nos princípios de gradualidade, flexibilidade e equilíbrio, bem como a incorporação da componente ambiental nas políticas setoriais e a inclusão das considerações ambientais na tomada de decisões para fortalecer a integração e a promoção do desenvolvimento sustentável por meio do apoio recíproco entre os setores ambientais e econômicos. Isso evita a adoção de medidas que restrinjam ou distorçam de maneira arbitrária ou injustificável a livre circulação de bens e serviços no âmbito do Mercosul, dando tratamento prioritário e integral às causas e fontes dos problemas ambientais. O objetivo desse acordo foi promover o desenvolvimento sustentável e a proteção do meio ambiente mediante a articulação entre as dimensões econômica, social e ambiental, contribuindo para uma melhor qualidade do meio ambiente e de vida da população.

A respeito do Acordo-Quadro sobre Meio-Ambiente do Mercosul de Assunção em 2001, Oliveira conclui que:

Uma leitura comparada dos textos em questão remete à conclusão de que para garantir a aprovação do texto em todas as instituições do Mercosul, os negociadores abdicaram de regular os temas contraditórios e as políticas ambientais específicas. Assim, o texto final do Acordo foi composto por apenas

22 O Fundo para a Convergência Estrutural do Mercosul (Focem) foi criado pela Decisão CMC n. ${ }^{\circ}$ 45/2004. Mais tarde, a Decisão CMC n. ${ }^{\circ}$ 18/2005 estabeleceu as normas para sua integração e funcionamento, e a Decisão CMC n. ${ }^{\circ}$ 1/2010 definiu seu regulamento atual.

23 Focem, Mercosul, "Fundo para a Convergência Estrutural do MERCOSUL (FOCEM)", consultado em 12 fev. 2018. https://focem.mercosur.int/pt/o-que-e-focem/.

24 Brasil. Acordo-Quadro sobre Meio Ambiente do Mercosul, consultado em 13 set. 2018. http://www2.camara. leg.br/legin/fed/decleg/2003/decretolegislativo-333-24-julho-2003-494160-acordo-quadro-1-pl.html. 
quatro capítulos, 10 artigos e um anexo, ao passo que o projeto do Protocolo previa 83 artigos e regulava inúmeros aspectos da agenda ambiental. Em suma, os negociadores tentaram resumir os pontos pacíficos e gerais deixando para o futuro a discussão de questões setoriais e dispositivos específicos. Assim, após a aprovação do Acordo-Quadro foi estabelecido o Protocolo Adicional ao Acordo-Quadro sobre Meio Ambiente do Mercosul em Matéria de Cooperação e Assistência Frente a Emergências Ambientais, 49 além de normas de direito derivado, tais como a Decisão 03/02 que prevê um projeto sobre gestão ambiental e produção mais limpa para pequenas e medias empresas. ${ }^{25}$

Na sequência histórica, em Montevidéu, no dia 9 de dezembro de 2005, firmou-se o Acordo-Quadro sobre Complementação Energética Regional entre os estadospartes do Mercosul e estados-associados, ${ }^{26}$ que visa ao desenvolvimento regional e sustentável, ao mesmo tempo que ratifica o direito da soberania dos países na gestão dos seus recursos energéticos, reconhece as potenciais complementariedades, as assimetrias em matéria energética e o direito dos povos de ter acesso à energia, além da importância da cooperação entre as partes, com o objetivo de apoiar e promover a complementação em matéria de energia, bem como harmonizar as respectivas estratégias nacionais. Esses propósitos reafirmam o objetivo comum de contribuir para a integração e segurança energética regional e para o desenvolvimento econômico e social sustentável. Além dos países do Mercosul (Argentina, Brasil, Paraguai, Uruguai e Venezuela), também foram signatários a Colômbia, o Chile e o Equador. O Decreto 7.377 de $1^{\circ}$ de dezembro de $2010^{27}$ ratificou os termos desse acordo, entrando assim em vigência no território brasileiro.

Com base nesse arcabouço jurídico, temos os fundamentos legais para a vinculação administrativa para a execução das ações que visam à integração energética do Mercosul. Essa integração permite ganhos ambientais, econômicos e sociais, de forma a contribuir para o desenvolvimento sustentável da região.

25 Oliveira, Liziane P. S., Direito ambiental do Mercosul: da negociação do protocolo adicional à ratificação do Acordo-Quadro sobre meio ambiente do Mercosul, consultado em 13 set. 2018. http://www.mpsp.mp.br/portal/page/ portal/documentacao_e_divulgacao/doc_biblioteca/bibli_servicos_produtos/bibli_boletim/bibli_bol_2006/ RDAmb_n.83.13.PDF.

26 Aladi. Acordos de Alcance Parcial, consultado em 13 set. 2018. http://www.aladi.org/nsfaladi/textacdos.nsf/ a69lef8a2b60522403256aa9005c077b/799f64328de300490325712c005f8dce?OpenDocument.

27 Brasil. Decreto 7.377, consultado em 13 set. 2018. http://www.planalto.gov.br/ccivil_03/_ato2007-2010/2010/ decreto/D7377.htm. 


\section{Gestão energética no Mercosul e Unasul}

Castaño e D’Apote explicam que "um modelo eficaz de integração energética é aquele que permite obter um abastecimento seguro e com o menor custo para cada participante. Quanto maior e mais integrado é o sistema, mais robusto e resistente ele é, permitindo uma melhor adaptação à evolução das necessidades das partes interessadas". ${ }^{28}$ A integração do setor energético ocorre num espaço geográfico que pode compreender cidades, estados e países, e, nesse sentido, Castaño e D'Apote argumentam que "dada a necessidade de satisfazer a demanda crescente de energia, bem como para a gestão eficiente e sustentável dos recursos naturais, é necessário pensar sobre o futuro da energia em uma região, de uma forma sistêmica". ${ }^{29}$

Esse processo de integração energética pode ser considerado como uma das partes de um processo mais amplo de integração econômica regional. Nessa direção, Rodrigues $^{28}$ lembra que, na década de 1950, "priorizava-se a integração dos mercados como ferramenta para auxiliar os processos nacionais de desenvolvimento por meio da industrialização baseada em políticas de substituição de importações. Já na década de 1990, a agenda para a integração estava focada no livre comércio e imbuída do contexto da liberalização econômica".

Queiroz e Vilela argumentam que "as experiências de integração na Europa vêm mostrando que o desenvolvimento da integração energética regional está sujeito a processos multidimensionais longos e sob uma complexidade muitas vezes imprevisível, pois são diversos os atores envolvidos nas decisões que, frequentemente, causam impactos no processo integrador". ${ }^{30}$

Rodrigues lembra que "na ALADI (Associação Latino-Americana de Integração) há [...] um acordo sobre Gás Natural entre a Argentina e o Uruguai e um Acordo de Cooperação e Integração Energética entre o Paraguai e o Uruguai [...] Acordo de Complementação Energética Regional com a participação dos países membros do MERCOSUL, além da Colômbia, do Chile e da Venezuela". ${ }^{31}$

28 Castaño, Agustin e Sylvie D’Apote, Integração energética regional, consultado em 13 fev. 2018: 1. https://6elaee.aladee.org/webtree/submit/download.php?subId=297\&final=yes.

29 Castaño e D’Apote, Integração energética regional.

30 Queiróz, Renato e Thaís Vilela, "Integração energética na América do Sul: motivações, percalços e realizações”. Blog Infopetro, postado em 24 maio 2010, consultado em 13 fev. 2018. https://infopetro.wordpress. com/2010/05/24/integracao-energetica-na-america-do-sul-motivacoes -percalcos-e-realizacoes/.

31 Rodrigues, Larissa Araujo. Análise Institucional e Regulatória da Integração de Energia Elétrica Entre o Brasil e os Demais Membros do MERCOSUL. Dissertação (Mestrado em Energia), Universidade de São Paulo, São 
No âmbito do Mercosul, Rodrigues destaca que "existe o Subgrupo de Trabalho No 9 (SGT No 9) destinado apenas às negociações sobre energia e um Grupo Ad Hoc sobre Biocombustíveis (GAHB). Além disso, o bloco possui alguns documentos assinados na área energética. Atualmente, são sete decisões, nove resoluções, um acordo de complementação energética e um memorando sobre biocombustíveis". ${ }^{32}$

A decisão Mercosul/CMC/DEC n. 10/1998 trata justamente sobre intercâmbio e integração elétrica no bloco e esclarece que os países-membros chegaram aos princípios de simetrias mínimas com as seguintes motivações:

CONSIDERANDO o interesse em desenvolver o intercâmbio de energia elétrica entre os Estados Partes do MERCOSUL, visando a complementação de seus recursos energéticos que permita otimizar a segurança do abastecimento aos usuários, o aproveitamento de excedentes de energia e sua capacidade instalada; COMPROMETIDOS a outorgar autorizações, licenças e concessões para a construção, funcionamento e exploração de interconexões que vinculem os sistemas elétricos dos Estados Partes, baseado no livre intercâmbio comercial de energia elétrica acordado entre empresas dos Estados Partes, as quais deverão respeitar a legislação, as normas reguladoras, técnicas e ambientais vigentes entre os países; ${ }^{33}$

Nesse sentido, Rodrigues sintetiza o processo de interligação elétrica no Mercosul com as seguintes considerações:

Fato é que o processo de integração energética, por meio dos intercâmbios de eletricidade entre os países que hoje formam o MERCOSUL, é possível, pois esses países possuem uma complementaridade entre os seus sistemas de geração e consumo de energia elétrica, devido aos seus distintos regimes hidrológicos e distintas condições bioclimáticas, o que lhes confere a possibilidade de otimizar a utilização de seus recursos (sazonalidade) (ARANGO, DYNER e LARSEN, 2006, p. 204; IEE, 2005a; OLIVEIRA, 2007, p. 134). Como apontam diversos estudos, ao explorar essa complementaridade é possível, além de promover um uso mais racional dos recursos naturais da região, (i) ou atender uma

Paulo, 2012. Consultado em 15 fev. 2018: 15. http://www.teses.usp.br/teses/disponiveis/86/86131/tde19042012-132609/publico/DissertCorrigLarissaAraujo Rodrigues.pdf.

32 Rodrigues, Análise Institucional e Regulatória, 15.

33 Mercosur. Mercosul/CMC/DEC n. ${ }^{\circ}$ 10/98, consultado em 12 fev. 2018. http://www.mercosur.int/msweb/ portal\%20intermediario/Normas/normas_web/Decisiones/PT/Dec_010_098_Memorando\%20Entend\%20 Interc\%C3\%A2mbio\%20Integ\%20El\%C3\%A9trica\%20MCS_Ata\%201_98.PDF (maiúsculas no original). 
mesma demanda com custos inferiores aos encontrados nos sistemas nacionais, através da energia não utilizada no país vizinho; (ii) ou aumentar a geração de energia a partir das próprias usinas já existentes, fazendo uso mais efetivo da capacidade instalada na região, expandindo a oferta também com custos inferiores, poupando combustíveis, investimentos e possibilitando um preço mais competitivo à energia elétrica (BEHRENS, 1990, p. 175-178; CAF, 2009; CHIPP, LATTARI, et al., 2010, p. 9; IEE, 2005b; OLIVEIRA, 2007, p. 134). ${ }^{34}$

Almeida e Haffner ${ }^{35}$ narram que a União das Nações Sul-Americanas (Unasul) se originou da convergência de diversos órgãos que surgiram de reuniões entre os países da América do Sul, iniciando-se com a I Reunião da Cúpula Sul-Americana entre os dias 30 de agosto e $1^{\circ}$ de setembro de 2000, em Brasília, onde foi proposta a criação da Iniciativa para a Integração da Infraestrutura Regional Sul-Americana (IIRSA) como uma proposta que visava promover uma efetiva coordenação de políticas entre os países da região e os blocos regionais existentes nas questões de transportes, energia, telecomunicações. Assim, o lançamento da IIRSA representou o primeiro passo dado na direção de uma integração regional de cunho energético, pois evidenciou o reconhecimento de que, na América do Sul, não é possível pensar em integração sem antes pensar em integração energética. ${ }^{36}$

Nas reuniões que seguiram, a II em 2002, em Guayaquil, no Equador, e a III em 2004, em Cusco e Ayacucho, no Peru, onde criaram a Comunidade Sul-Americana de Nações (Casa). A Casa tinha como meta principal o desenvolvimento e aperfeiçoamento dos seguintes temas: concertação e coordenação política e diplomática; promoção de uma zona de livre comércio entre o Mercosul, a Comunidade Andina (CAN) e o Chile; promoção da integração física, energética e de comunicações; promoção da cooperação horizontal nas áreas da ciência, da educação e da cultura; promoção da interação entre empresas e sociedade civil. Em 2007, em Isla Margarita, na Venezuela, realizou-se a I Cúpula Energética da Casa, na qual foi assinada a Declaração de Margarita, que reconhece que a integração da América do Sul pela via energética constitui um dos principais eixos estruturais na construção de um futuro espaço de unidade sul-americana. Assim, segundo Almeida e Haffner, "ao final da Cúpula de Isla Margarita os presidentes e representantes dos países

Rodrigues, Análise Institucional e Regulatória, 16.

35 Almeida, Adriano P. e Jacqueline Haffner A., As tentativas de complementação energética na América do Sul: da Cepal a Unasul. 2017, consultado em 13 set. 2018. http://seer.pucgoias.edu.br/index.php/baru/article/ view/5836.

36 Almeida e Haffner, As tentativas de complementação energética na América do Sul. 
da América do Sul mudaram o nome da CASA para UNASUL (União de Nações Sul-Americanas) —criada oficialmente em 23 de maio de 2008 por ocasião da I Reunião Extraordinária de Chefes de Estado e de Governo da UNASUL realizada em Brasília". ${ }^{37}$

O surgimento da Aliança do Pacífico, em 2012, também criou desafios à unidade e desenvolvimento da Unasul, pois três dos doze países-membros da União Sul-Americana —Chile, Colômbia e Peru—são membros fundadores dessa Aliança e outros três - Equador, Paraguai e Uruguai- participam dela na condição de membros observadores, em função de que os membros dessa Aliança se comprometeram a uma integração profunda com a área Ásia-Pacífico, em conflito com os interesses da Unasul. Mesmo assim, a noção de que o sucesso da integração sul-americana passa pela integração energética se materializou na realização da I Reunião de Cúpula Energética, de forma a minimizar as assimetrias existentes entre os países da região, em especial com o Brasil. ${ }^{38}$

\section{Gás natural}

A integração energética na região do Cone Sul inclui seis países que já têm uma história de intercâmbios de energia e infraestrutura de interconexões das redes de eletricidade e de gás natural, sendo quatro deles membros do Mercosul (Argentina, Brasil, Paraguai e Uruguai), um está em processo de adesão (Bolívia) e um apenas associado (Chile). Sobre isso, Castaño e D’Apote reiteram: "as exportações transfronteiriças de gás iniciaram em 1972 quando foi finalizada a construção do primeiro gasoduto binacional do Cone Sul entre Bolívia e Argentina. Atualmente, existem na região 17 gasodutos transfronteiriços: 9 entre Argentina e Chile, 2 entre Argentina e Bolívia, 3 entre Argentina e Uruguai, 1 entre Argentina e Brasil, 2 entre Bolívia e Brasil". ${ }^{39}$

Nesse sentido, Castaño e D’Apote explicam que "o Cone Sul tem como agentes principais a Bolívia, Argentina e Brasil. A Bolívia é a grande exportadora de gás natural da região e tem contratos de exportação de longo prazo com o Brasil e com a Argentina". ${ }^{40}$

\footnotetext{
Almeida e Haffner, As tentativas de complementação energética na América do Sul. Destaques no original. Almeida e Haffner, As tentativas de complementação energética na América do Sul.

Castaño e D'Apote, Integração energética regional, 2.

Castaño e D’Apote, Integração energética regional, 2-3.
} 
O Acordo-Quadro sobre Complementação Energética Regional entre os Estados-partes do Mercosul e os Estados-associados ${ }^{41}$ prevê, em seu artigo $6^{\circ}$, a interconexão de redes de gasodutos e outros dutos de hidrocarbonetos, bem como a cooperação na prospecção, exploração, aproveitamento e industrialização dos hidrocarbonetos, constituindo fundamento jurídico vinculante ao dever da promoção da integração regional dos países signatários no tocante ao gás natural.

Mapa 1. Rede de gasodutos no Cone Sul

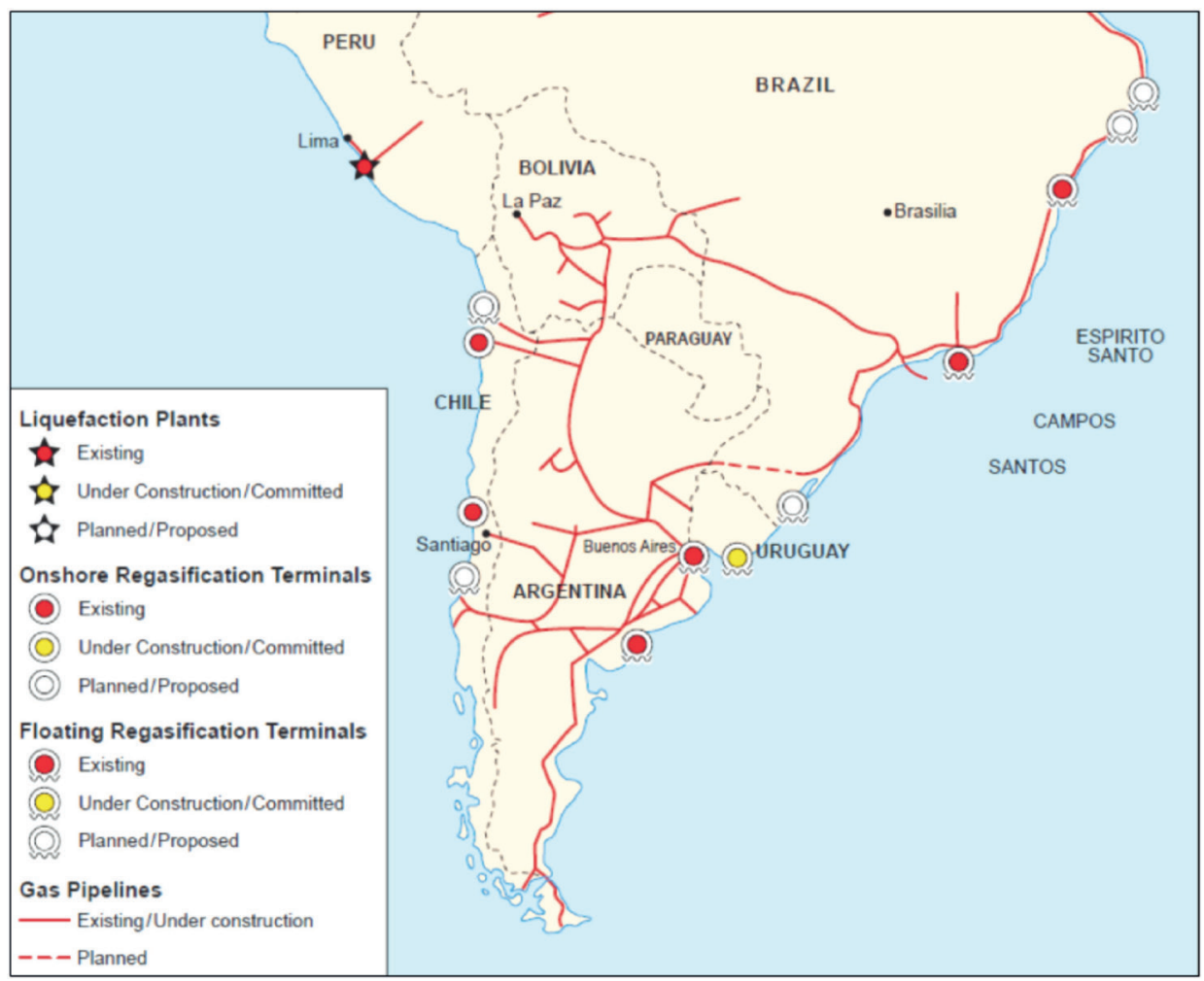

Fonte: Prysma E\&T Consultores (2016). ${ }^{27}$

$41 \quad$ Aladi, Acordos de Alcance Parcial. 
Tabela 1. Oferta e demanda de gás natural nos países do Cone Sul, 2015 (MMm³/d)

\begin{tabular}{|c|c|c|c|}
\hline & Produção disponible & Consumo & Importação Líquida \\
\hline Argentina & 100,0 & 130,2 & 30,2 \\
\hline Bolívia & 57,5 & 10,0 & $(46,8)$ \\
\hline Basil & 52,2 & 98,6 & 50,4 \\
\hline Chile & - & 10,7 & 11,5 \\
\hline Paraguai & - & - & - \\
\hline Uruguai & - & 0,2 & 0,2 \\
\hline
\end{tabular}

Fonte: Ministério de Minas e Energia, Brasil (2016), BP Statistical Review (2016), Ministerio de Industria, Energía y Minería, Uruguai (2016). ${ }^{27}$

\section{Energia elétrica}

O intercâmbio de energia elétrica, via conexões entre os países, é bem menor do que a existente quanto ao gás natural, conforme se observa na tabela 2 . Segundo Castaño e D'Apote, "isso se deve às importantes dotações de recursos energéticos de cada país, mas também à postura dos países de manter sua segurança energética e depender minimamente dos recursos externos. Historicamente isso resultou em um obstáculo à maior integração elétrica entre os países". ${ }^{42}$

Tabela 2. Oferta e demanda de energia elétrica nos países do Cone Sul, 2015 (GWh)

\begin{tabular}{|c|c|c|c|}
\hline & Geração & Consumo & Importação Líquida \\
\hline Argentina & 135,215 & 132,100 & 1.600 \\
\hline Bolívia & 8,335 & 7.946 & - \\
\hline Brasil & 539.887 & 565.273 & 33.167 \\
\hline Chile & 71.680 & 60.817 & - \\
\hline Paraguai & 55.744 & 10.576 & -41.127 \\
\hline Uruguai & 13.328 & 10.565 & -1.319 \\
\hline
\end{tabular}

\footnotetext{
* Consumo estimado
}

Fonte: Ministério de Minas e Energia, Brasil (2016), Cammesa (2016), Asociación Gremial de Generadoras de Chile (2016), Ministerio de Obras Públicas y Comunicaciones, Paraguai (2015), Ministerio de Industria, Energía y Minería, Uruguai (2016). ${ }^{43}$

Acredita-se que a própria opção, no passado, de os países terem optado por uma frequência de operação das redes elétricas que diferem entre si, $50 \mathrm{hz}$ ou $60 \mathrm{hz}$, foi uma questão ligada à segurança estratégica em casos de conflitos. Dos países do Cone Sul, apenas o Brasil usa 60hz e, do Mercosul, acrescenta-se a Venezuela.

42 Castaño e D’Apote, Integração energética regional, 4.

43 Castaño e D'Apote, Integração energética regional, 4. 
A interligação entre Brasil e Venezuela ocorre ao norte do território brasileiro, no estado de Roraima. Essa conexão foi estabelecida em 1997 entre a Centrais Elétricas do Norte do Brasil S.A. (Eletronorte) e a Electrificación del Caroní. O empreendimento consiste em um sistema de transmissão, em $400 \mathrm{kV}$ e $230 \mathrm{kV}$, misto brasileiro-venezuelano que interliga a cidade de Boa Vista ao complexo hidrelétrico de Guri-Macágua, com extensão de 676 km, sendo 191 km no território brasileiro. Pelo lado do Brasil, o sistema compreende a subestação de Boa Vista, com tensão de 230/69 kV, e a linha de transmissão, localizada ao longo da BR-174, entre as subestações de Boa Vista e Santa Elena de Uiarén, que fica na fronteira entre os dois países (Eletronorte, 2007). ${ }^{44}$

E, na América do Sul, dos países que operam na frequência de $60 \mathrm{hz}$, apenas o Brasil e o Peru fazem divisa com países que operam na frequência de $50 \mathrm{hz}$, conforme ilustrado no mapa 2 a seguir.

Mapa 2. Linhas de transmissão de energia elétrica na América do Sul

\section{Interconexões existentes e em estudo}

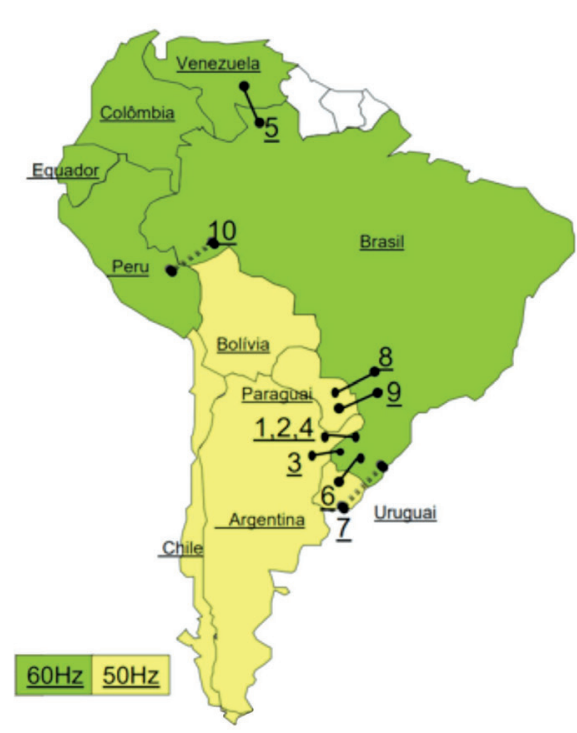

\begin{tabular}{llr} 
Interconexão & Situação & MW \\
Argentina & & \\
\hline 1. Garabi I & Operando & 1018 \\
\hline 2. Garabi II & Operando & 1160 \\
\hline 3. Uruguaiana & Operando & 50 \\
\hline 4. UHE Garabi & Em estudo & 1200 \\
Venezuela & & \\
\hline 5. Boa Vista & Operando & 200 \\
Uruguai & & \\
\hline 6. Rivera & Operando & 70 \\
\hline 7. San Carlos & Em estudo & 500 \\
\hline Paraguai & & \\
\hline 8. Foz lguacu & Operando & 50 \\
\hline 9. Itaipu & Operando & 6300 \\
\hline Peru & & \\
\hline 10. Projetos Hidro & Em estudo & 7564
\end{tabular}

Fonte: Chipp, Hermes (2009). ${ }^{45}$

44 Castro, Nivalde J. et al. "Importância e Dificuldades da Integração Elétrica na América do Sul", em Perspectivas para a Integração da América Latina, coord. Desiderá Neto, Walter Antonio e Teixeira, Rodrigo Alves (Brasília: Ipea, 2014), 122.

45 Queiróz e Vilela, Integração energética na América do Sul. 
Para se realizar a integração de redes que operam em $50 \mathrm{hz}$ com outras que operam em $60 \mathrm{hz}$, é necessária uma subestação de energia elétrica com equipamentos que realizam a conversão de uma frequência para outra, o que implica consideráveis investimentos em infraestrutura. Quanto maior for a capacidade de energia a ser transmitida, maiores e mais dispendiosos serão os equipamentos. Há ainda que se ressalvar que há uma perda energética nessa conversão, pois a eficiência da conversão não é da integralidade da energia. Conforme se observa no mapa 2, já existem algumas interconexões entre o Brasil e a Argentina, o Paraguai e o Uruguai, que realizam essa conversão de frequência, e outras ainda em estudo.

O Brasil possui três interligações em operação com a Argentina. A primeira é a de Uruguaiana, as outras são de Garabi I e Garabi II. A principal interligação com a Argentina ocorre, entretanto, com as linhas referentes à Garabi I e II. Esta é uma interligação de grande porte e se dá pelas conversoras de frequência Garabi I, com capacidade nominal de 1.100 MW, e Garabi II, também, com capacidade nominal de 1.100 MW. "Por estar ligada ao sistema de 500 kV do SIN, ${ }^{46}$ essa interligação apresenta uma grande capacidade de intercâmbio entre os dois países, e tem sido de extrema importância em épocas de crise energética e/ou emergências, permitindo ainda assistência até de outros países, como o Uruguai, que recebeu energia do Brasil passando pela Argentina." ${ }^{47}$

Castaño e 'D'Apote explicam que "as interconexões elétricas na região são de dois tipos: pequenas interconexões fronteiriças e hidrelétricas binacionais de grande porte. Ao contrário dos gasodutos, que geralmente possuem uma direção de fluxo bem definida, os fluxos de energia elétrica são bidirecionais, podendo um país tanto importar como exportar energia". ${ }^{48}$

Rodrigues lembra ainda que "os projetos de integração relacionados à energia entre o Brasil e os demais membros do MERCOSUL surgiram muito antes da formação do bloco. [...] os mais antigos sendo a usina hidroelétrica Itaipu Binacional e a interligação de Acaray, ambos realizados entre Brasil e Paraguai" . ${ }^{49}$ Além dessas, Rodrigues também destaca que "Paraguai e Argentina também construíram uma central binacional, a usina hidroelétrica Yacyretá, que foi fruto do Tratado de Yacyretá, assinado pelos dois países em 1973 (EBY, 2011). Uma terceira central

\footnotetext{
Sistema Interligado Nacional Brasileiro, que atende a aproximadamente $98 \%$ da carga de energia brasileira. Castro et al., "Importância e dificuldades da integração elétrica na América Do Sul".

Castaño e D’Apote, Integração energética regional, 4.

Rodrigues, Análise Institucional e Regulatória, 11.
} 
hidroelétrica binacional, a usina de Salto Grande, foi construída por Argentina e Uruguai a partir de 1974 e oficialmente inaugurada em 1983 (CTMSG, 2011)".50 Existe ainda o projeto para a construção de uma nova central entre Brasil e Argentina, o projeto de Garabi-Panambi, que ainda está em fase de estudos, nos quais, entre outras, devem ser equacionadas várias questões socioambientais.

As centrais binacionais, como exposto, surgiram como solução técnica para resolver questões de abastecimento e geração de energia, ainda antes do início da formação dos blocos regionais, como o Mercosul. Rodrigues explica que, "além das centrais hidroelétricas binacionais, a integração energética por meio dos intercâmbios de energia elétrica também ocorre por interligações não associadas às centrais e que conectam seus mercados de eletricidade" ${ }^{51}$

A energia elétrica gerada usualmente é injetada diretamente nas redes de distribuição, o que faz com que a geração e o consumo sejam quase simultâneos, tendo em vista a altíssima velocidade que a energia elétrica percorre a linha de transmissão. Isso gera uma capacidade ociosa de geração, que pode ser reduzida quando se tem mais fontes de geração e pontos de consumo interligados num mesmo sistema de distribuição, o que por consequência eleva a eficiência e o rendimento energético. Rodrigues apresenta um estudo "que verificou por meio de simulações os custos de operação dos sistemas de eletricidade do Brasil e da Argentina com a integração e sem a integração, chegando à conclusão de que os mesmos quando integrados apresentam custos de operação cerca de 5\% inferiores aos custos de quando operados de maneira isolada (IEE, 2005b)". ${ }^{2}$

Além dessa redução de custos, a integração aumenta a confiabilidade do fornecimento de energia, pois um eventual defeito numa unidade geradora pode ser contornado com o aumento do fornecimento pelas outras unidades geradoras ou uma ruptura numa linha de transmissão pode ser equacionada pela redundância das redes de distribuição. Nesse sentido, Rodrigues traz um estudo "desenvolvido pelo IEE, que analisou por meio de simulações o impacto das interconexões de energia elétrica entre Brasil e Argentina na otimização do uso dos recursos energéticos desses países e verificou que se a operação das mesmas tivesse sido antecipada teria sido possível

Rodrigues, Análise Institucional e Regulatória, 13.

Rodrigues, Análise Institucional e Regulatória, 15.

Rodrigues, Análise Institucional e Regulatória, 16. 
evitar ou minimizar a crise de abastecimento elétrico que o Brasil vivenciou entre 2001 e 2002 (IEE, s.d.)". 53

Há ainda o ganho logístico que permite alcançar mercados mais distantes, especialmente porque a energia elétrica não gera acréscimo de custo para ser transportada. Rodrigues traz que "por meio das interconexões, os agentes do setor elétrico podem conquistar ganhos de escala e a expansão de seus mercados, já que só conseguem vender seu produto (energia elétrica) para fora da área onde estão estabelecidos com a existência de uma infraestrutura para o transporte, o que só é viável nesse caso na própria região (BEHRENS, 1990, p. 176; QUINTO, 2007, p. 65)". ${ }^{54}$

O Acordo-Quadro sobre Complementação Energética Regional entre os Estados-partes do Mercosul e os Estados-associados ${ }^{55}$ prevê, em seu artigo $6^{\circ}$, a interconexão das redes de transmissão elétrica, bem como a cooperação no desenvolvimento e uso das fontes de energia renováveis e energias alternativas, constituindo fundamento jurídico vinculante ao dever da promoção da integração regional dos países signatários no tocante ao gás natural.

\section{Considerações finais}

A questão da geração de energia toma um dos papéis principais quando se trata de questões de sustentabilidade e desenvolvimento, pois a baixa eficiência de conversão energética nos dispositivos que se utilizam para gerar energia, em especial a energia elétrica, tem levado a um consumo dos recursos naturais de forma insustentável, além do que a matriz energética baseada em combustíveis fósseis emite gases que produzem o efeito estufa, elevando a temperatura global, o que leva a inúmeros problemas ambientais.

Nesse sentido, a energia é estratégica e essencial para o desenvolvimento do Estado e seu crescimento econômico e social, motivo para que a ciência do direito, em conjunto com as ciências correlatas, tais como física, química, geologia e engenharia, busquem criar formas de estimular o investimento nas formas de geração de energia que visem à sustentabilidade e preservação do meio ambiente; com base em um projeto amplo e exequível, realizem a transição da atual realidade de geração e

\footnotetext{
Rodrigues, Análise Institucional e Regulatória.

4 Rodrigues, Análise Institucional e Regulatória, 16-17.

55 Aladi, Acordos de Alcance Parcial.
} 
transmissão de energia para aquela que mostra ser a solução ideal e em sintonia com estado da arte do conhecimento.

A compreensão que o desenvolvimento não pode ser medido apenas pela perspectiva econômica, mas também pela qualidade de vida, que inclui a perspectiva proposta por Amartya Sen de considerar como desenvolvimento a possibilidade de as pessoas levarem o tipo de vida que elas valorizam, é salutar para o entendimento da importância ambiental para a vida humana.

Nesse sentido, Vainer" ${ }^{56}$ expõe que "vivemos, em nosso continente, em sociedades profundamente desiguais, nas quais parcelas expressivas das populações estão à margem de processos decisórios de que dependem tanto seu cotidiano quanto seu futuro", e a integração energética pode ajudar na redução das desigualdades e a promover oportunidades de desenvolvimento social e econômico, com grandes possibilidades de ganhos ambientais. Para alcançar tal intento, Vainer considera que "será indispensável avançar, em primeiro lugar, na constituição de processos de discussão e decisão que, de fato, permitam incorporar de maneira informada representações consistentes da sociedade civil continental. Esse constitui um desafio bem maior que a construção de barragens, usinas ou linhas de transmissão". ${ }^{57}$

A questão institucional e regulatória tem se apresentado como um dos principais entraves para o avanço do processo de integração dos sistemas de eletricidade no Mercosul. Dessa forma, conhecer a análise econômica do direito (AED) é essencial para a efetividade das regulações públicas e sentenças judiciais. $\mathrm{O}$ interesse dos Estados nas regulações que realiza seria conciliar o desenvolvimento econômico, que possibilita os recursos para o Estado efetivar os direitos sociais a que se propõe, com justiça social, atuando na exata medida da necessidade de sua intervenção, já que esta costuma ser negativa ao prejudicar a concorrência.

O estímulo institucional e regulatório do Mercosul, que visa aumentar a geração de energia por fontes renováveis e não emissoras de carbono, é importante para o desenvolvimento sustentável da região. Também é muito importante a ampliação da interligação dos sistemas elétrico e de gás natural, contanto que este último não seja energia renovável, pois permite por si só uma redução de custo operacional

\footnotetext{
Vainer, Carlos e Nuti, Mírian, A integração energética sul-americana: subsídios para uma agenda socioambiental (Brasília: INESC, 2008), consultado em 13 set. 2018. http://www.inesc.org.br/biblioteca/textos/livros/ a-integracao-energetica-sul-americana: 33.

57 Vainer e Nuti, A integração energética sul-americana, 33.
} 
juntamente com a otimização do uso da capacidade de geração de energia já existente, evitando o uso de recursos para a construção de novas unidades de geração e sua consequente pegada ambiental. Numa região geográfica continental como a América do Sul, ganhos como os estimados em 5\% significam uma grande economia de recursos econômicos e ambientais.

A interligação dos sistemas de distribuição de energia elétrica permite ainda um ganho de estabilidade e confiabilidade, que possibilita evitar ou minimizar situações que poderiam levar a uma crise de abastecimento elétrico. Promove um ganho logístico nas operações no mercado de energia ao aumentar o número de fornecedores e consumidores acessíveis pela rede de distribuição, e viabilizar uma maior concorrência entre os operadores desse setor. Num sistema capitalista, isso é importante para que exista uma pressão no sentido da eficiência e, por consequência, da meritocracia.

Assim, a integração energética no âmbito do Mercosul e demais países vizinhos, já incorporada aos ordenamentos jurídicos dos países signatários do Acordo-Quadro sobre Complementação Energética Regional entre os estados-partes do Mercosul e os estados-associados, ${ }^{58}$ traz ganhos econômicos, estruturais e ambientais. A adequada solução da regulação trará resultados rápidos e eficazes para todos os Estados participantes. As mudanças sociais e tecnológicas que se avizinham tendem a aumentar a demanda por energia elétrica e, com as soluções de geração de energia renovável ganhando viabilidade econômica, as limitações ao desenvolvimento serão cada vez mais pautadas na sustentabilidade ambiental.

\section{Referências}

Aladi. Acordos de Alcance Parcial. http://www.aladi.org/nsfaladi/textacdos.nsf/ a69lef8a2 b60522403256aa9005c077b/799f64328de300490325712c005f8dce?OpenDocum ent, consultado em 13 set. 2018.

Almeida, Adriano P. e Jacqueline Haffner. A. As tentativas de complementação energética na América do Sul: da Cepal a Unasul. 2017, consultado em 13 set. 2018. http://seer. pucgoias.edu.br/index.php/baru/article/view/5836.

Brasil. Acordo-Quadro sobre Meio Ambiente do Mercosul, consultado em 13 set.2018. http://www2.camara.leg.br/legin/fed/decleg/2003/decretolegislativo-333-24-julho2003-494160-acordo-quadro-1-pl.html.

58 Aladi, Acordos de Alcance Parcial. 
Brasil. Decreto 7.377, consultado em 13 set. 2018. http://www.planalto.gov.br/ccivil_03/_ato2007-2010/2010/decreto/D7377.htm.

Breve História da Terra, consultado em 23 dez. 2017. http://www.cprm.gov.br/publique/ Redes-Institucionais/Rede-de-Bibliotecas---Rede-Ametista/Canal-Escola/Breve-Historiada-Terra-1094.html.

Castaño, Agustin e Sylvie D’Apote. Integração energética regional, consultado em 13 fev. 2018:

1. https://6elaee.aladee.org/webtree/submit/download.php?subId=297\&final=yes.

Castro, Nivalde J. et al. "Importância e dificuldades da integração elétrica na América do Sul". Em Perspectivas para a Integração da América Latina, coord. por Desiderá Neto, Walter Antonio e Teixeira, Rodrigo Alves. Brasília: Ipea, 2014.

Coase, Ronald H. "The Problem of Social Cost". Journal of Law and Economics 3(out. 1960).

Conceitos básicos, consultado em 23 dez. 2017. https://pt.scribd.com/doc/50498774/ Conceitos-Basicos.

Ferreira, Guilherme Augusto Guimarães; Clarissa Correa Neto Ribeiro, "A estrutura institucional do Mercosul: análise da evolução dos espaços de participação social”, In: Anais do II Simpósio Internacional Pensar e Repensar a América Latina, São Paulo, 2016, consultado em 12 fev. 2018. https://sites.usp.br/prolam/wp-content/uploads/sites/35/2016/12/Ferreira_ Ribeiro_II-Simposio-Internacional-Pensar-e-Repensar-a-America-Latina.pdf.

Mercosul, "Fundo para a Convergência Estrutural do MERCOSUL (FOCEM)", consultado em 12 fev. 2018. https://focem.mercosur.int/pt/o-que-e-focem/.

Folloni, André. "A complexidade ideológica, jurídica e política do desenvolvimento sustentável e a necessidade de compreensão interdisciplinar do problema". Revista Direitos Humanos Fundamentais 14, 1 (jan.-jun. 2014): 63-91.

Freitas, Vladimir Passos de. "A desejada e complexa conciliação entre desenvolvimento econômico e proteção do meio ambiente no Brasil". Revista Direito Ambiental e Sociedade 4, 1(semestral, 2014): 235-263. Consultado em 22 dez. 2017. http://www.ucs.br/ etc/revistas/index.php/direitoambiental/ article/view/3692/2115.

Halliday, David, Robert Resnick e Jearl Walker. Fundamentos de física, volume 1: mecânica. $8^{a}$ ed. Rio de Janeiro, LTC, 2008.

World Economic Forum, Harnessing the Fourth Industrial Revolution for the Earth. Consultado em 29 dez. 2017. http://www3.weforum.org/docs/WEF_Harnessing_the_4IR_for_ the_Earth.pdf.

Ipiranga, Ana Silva Rocha; Godoy, Arilda Schmidt; Brunstein, Janette, "RAM. Revista de Administração Mackenzie", RAM, Rev. Adm. Mackenzie (Online) vol.12 no.3 São Paulo Jun 2011, consultado em 22 dez. 2017. http://www.scielo.br/scielo.php? script=sci_arttext\&pid=S1678-69712011000300002.

Kaku, Michio. A Física do Futuro. Lisboa: Bizâncio, 2011. 
Mercosur. Mercosul/CMC/DEC n. ${ }^{\circ}$ 10/98. Consultado em 12 fev. 2018. http://www. mercosur.int/msweb/portal\%20intermediario/Normas/normas_web/Decisiones/ PT/Dec_010_098_Memorando\%20Entend\%20Interc\%C3\%A2mbio\%20Integ\%20 El\%C3\%A9trica\%20MCS_Ata\%201_98.PDF.

Milaré, Edis. Direito do Ambiente. 8a ed. rev. atual. e ampl. São Paulo: RT, 2013.

North, Douglass Cecil. Institutions, institutional change and economic performance. Cambridge: University Press, 1990.

Oliveira, Liziane P. S. Direito ambiental do Mercosul: da negociação do protocolo adicional à ratificação do Acordo-Quadro sobre meio ambiente do Mercosul. Consultado em 13 set. 2018. http://www.mpsp.mp.br/portal/page/portal/documentacao_e_divulgacao/ doc_biblioteca/bibli_servicos_produtos/bibli_boletim/bibli_bol_2006/RDAmb_n.83.13. PDF.

Queiróz, Renato e Thaís Vilela, Integração energética na América do Sul: motivações, percalços e realizações. Blog Infopetro, em Energia, em 24 maio 2010, às 00:30, consultado em 13 fev. 2018. https://infopetro.wordpress.com/2010/05/24/integracao-energetica-naamerica-do-sul-motivacoes -percalcos-e-realizacoes/.

Rodrigues, Larissa Araujo. Análise Institucional e Regulatória da Integração de Energia Elétrica Entre o Brasil e os Demais Membros do MERCOSUL. Dissertação (Mestrado em Energia), Universidade de São Paulo, São Paulo, 2012. Consultado em 15 fev. 2018. http://www.teses.usp.br/teses/disponiveis/86/86131/tde-19042012-132609/publico/ DissertCorrigLarissaAraujo Rodrigues.pdf.

Scherwitz, Débora Perilo. As visões antropocêntrica, biocêntrica e ecocêntrica do direito dos animais no Direito Ambiental. Consultado em 29 dez. 2017. http://revista.zumbidospalmares. edu.br/images/stories/pdf/edicao-3/visoes-biocentrica-ecocentrica.pdf.

Sen, Amartya. Development as freedom. Nova York: Knoph, 2000.

Vainer, Carlos e Nuti, Mírian, A integração energética sul-americana: subsídios para uma agenda socioambiental, Brasília: INESC, 2008, consultado em 13 set. 2018. http://www.inesc. org.br/biblioteca/textos/livros/ a-integracao-energetica-sul-americana. 